\title{
Early clearance of serum HE4 and CA125 in predicting platinum sensitivity and prognosis in epithelial ovarian cancer
}

\author{
Yan Rong ${ }^{1,2}$ and $\mathrm{Li} \mathrm{Li}^{1,2^{*}}$
}

\begin{abstract}
Objectives: To assess the clinical value of early clearance of HE4 and CA125 for platinum sensitivity and prognosis in patients with ovarian cancer.

Method: HE4 and CA125 value including clinical data of 89 patients with ovarian cancer were collected. The clearance of HE4 and CA125 were assessed base on the platinum sensitivity, two-year PFS, PFS and OS.

Results: Sixteen patients were classified as platinum resistant and 73 as platinum sensitive according to the response to platinum-base chemotherapy. When HE4 clearance after 3rd cycle chemotherapy or CA125 clearance after 1st cycle chemotherapy, it gave the highest AUC of 0.788 , with $100 \%$ of sensitivity and $57.5 \%$ of specificity respectively between platinum resistant and platinum sensitive group. In addition, 59 patients were classified as two-year PFS group and 30 as not achieved two-year PFS group according to obtaining two-year PFS or not. It gave the highest AUC of 0.730 , with $83.3 \%$ of sensitivity and $62.7 \%$ of specificity respectively when HE4 clearance after 3rd cycle chemotherapy or CA125 clearance after 1st cycle. The prolonged PFS and OS were significantly associated by the clearance of HE4 after 3rd cycle chemotherapy $(p<0.0001, p<0.0001)$ as well as CA125 after 1st cycle chemotherapy $(p<0.0001, p<0.0001)$.

Conclusions: Our data suggested that the early clearance of HE4 and CA125 could predict platinum response and prognosis in patients with ovarian cancer. Monitoring the HE4 and CA125 during first-line chemotherapy might be helpful in predicting platinum sensitivity and risk to progress and relapse.
\end{abstract}

Keywords: Platinum sensitivity, Prognosis, HE4, CA125, Clearance, Chemotherapy

\section{Introduction}

Epithelial ovarian cancer (EOC) is the leading cause of mortality among gynecological cancer [2]. Due to the lack of typical clinical performance and reliable screening methods, approximately $75 \%$ of patients were diagnosed at advance disease with a poor prognosis. $30-50 \%$ of advanced patients will relapse within

\footnotetext{
* Correspondence: lili@gxmu.edu.cn

'Department of Gynecologic Oncology, Guangxi Medical University Cancer Hospital, 71 Hedi Road, Nanning, Guangxi 530021, People's Republic of China ${ }^{2}$ Key Laboratory of Early Prevention and Treatment of Regional High-Incidence Tumors, Ministry of Education, No.22 Shuangyong Road, Nanning 530021, People's Republic of China
}

5 years after standard surgery and platinum-based chemotherapy. Although the inhibition of the poly ADP-ribose polymerase has become an attractive therapeutic strategy in patients of epithelial ovarian cancer, early identification of drug-resistant or highrisk patients and taking hierarchical management is still crucial for improving prognosis.

Since patients with EOC have no measurable target lesion after initial surgery, it is difficult to assess the treatment response with gynecological examination and image. Effort has been made to find out reliable biomarker for monitoring therapeutic response and

C C The Author(s). 2021 Open Access This article is licensed under a Creative Commons Attribution 4.0 International License, which permits use, sharing, adaptation, distribution and reproduction in any medium or format, as long as you give appropriate credit to the original author(s) and the source, provide a link to the Creative Commons licence, and indicate if changes were made. The images or other third party material in this article are included in the article's Creative Commons licence, unless indicated otherwise in a credit line to the material. If material is not included in the article's Creative Commons licence and your intended use is not permitted by statutory regulation or exceeds the permitted use, you will need to obtain permission directly from the copyright holder. To view a copy of this licence, visit http://creativecommons.org/licenses/by/4.0/ The Creative Commons Public Domain Dedication waiver (http://creativecommons.org/publicdomain/zero/1.0/) applies to the data made available in this article, unless otherwise stated in a credit line to the data. 
detecting relapse in EOC. Cancer antigen 125 (CA125) is the most common serum biomarker for judging treatment response and monitoring recurrent in EOC. Our previous study demonstrated that the median PFS and OS of patients with serum CA125 who had a logarithmic decrease or a decrease to normal within 1 month after treatment were better than those of with a nonlogarithmic decrease or a decrease to normal that took longer than 1 month [25]. However, the single role of serum CA125 in predicting prognosis and platinum sensitivity still remains controversial $[7,17,22]$. Therefore, there is still an urgent need to find more promising biomarkers for monitoring the prognosis of ovarian cancer.

Human epididymis protein 4 (HE4), has been proved to be a reliable biomarker for detecting ovarian cancer with a sensitivity of $76 \%(95 \% \mathrm{CI}, 0.72-0.80)$ and a specificity of 94\% (95\%CI, 0.90-0.96) [29] and approved by the Food and Drug Administration in Unite State as a novel tumor biomarker for the diagnosis of ovarian cancer. The exploration of the value of this glycoprotein in predicting prognosis in ovarian cancer is still ongoing $[6$, $10,15,16]$. But there are seldom study concern with the correlation of early clearance of serum HE4 combined with CA125 during first-line treatment with platinum sensitivity and prognosis. The aim of this study is to evaluate the role of early clearance of HE4 and CA125 in predicting platinum sensitivity and prognosis in epithelial ovarian cancer.

\section{Materials and methods}

\section{Patients and clinical data}

The retrospective study was conducted in the Guangxi Medical University Cancer Hospital of china from July 2012 to December 2018. Patients diagnosed with epithelial ovarian cancer by histopathology with full serum HE4 and CA125 value and clinical record were available for review. Inclusion criteria were: 1) Initially treated with staging surgery or optimal cytoreductive surgery, including total hysterectomy, bilateral oophorectomy and salpingectomy, peritoneal washing, omentectomy, pelvic/para-aortic nodal dissection, and multiple peritoneal biopsies (multivisceral resection including en bloc resections with bowel resection, upper abdominal procedures, and extensive peritonectomy are required to achieve optimal tumor debulking when necessary). 2) Patients with stage IC and higher stage received platinum-based combined chemotherapy for $6-8$ cycles after surgery. 3) Good nutritional status without other cancer. Exclusion criteria were:1) Death due to nononcological reasons. 2) Lacking of follow-up after treatment.

Responds to treatment and progression were evaluated according to the guidelines of the Gynecology Cancer Intergroup (GCIG) [23] and the Response Evaluation
Criteria in Solid Tumors (RECIST) criteria [11]. PFS was defined as the length of time between the initial treatment to the occurrence of the progress or relapse. OS was defined as the length of time between the initial treatment to death. According to the respond to chemotherapy, patients with recurrence within 6 months after the completion of first-line platinum chemotherapy were defined as platinum resistant. Patients who developed recurrence with an interval $>6$ months were defined as platinum sensitive patients [8].

The study was compliant with the Declaration of Helsinki, and approved by the Ethics Committee of Guangxi Medical University Cancer Hospital. Informed consents of all treatments and examinations have been obtained from patients or their families.

\section{Test of HE4 and CA125 value}

Serum HE4 and CA125 concentration of each patient were measured at the time of pretreatment, each postchemotherapy and recurrence. The tests were performed using an electro-chemiluminescence immunoassay (Roche, Diagnostics, Inc., Mannheim, Germany, performed according to the manufacturer's specifications) at the departmental laboratory of Guangxi Medical University Cancer Hospital. The normal value range of HE4 is less than or equal to $70 \mathrm{pmol} / \mathrm{L}$ as suggested by Moore et al. [19], and the normal value of CA125 is less than or equal to $35 \mathrm{U} / \mathrm{ml}$.

\section{Statistical analyses}

All the statistical analyses were conducted by SPSS 25.0 Software. T-test was used for the comparison between groups. The area under the curve (AUC) was used to calculate with a receiver operating characteristics (ROC) in predicting platinum sensitivity and two-year survival. The Kaplan-Meier survival curve and long rank test were used to assess the influence of HE4 and CA125 on PFS and OS. Cox regression models was used to conduct the univariate and multivariate analyses. A two-tailed probability of $p<0.05$ was defined as a statistically significant.

\section{Results}

\section{Patients' characteristics}

A total of 89 patients with EOC were included in the study. All patients were followed up to December 31, 2019. At the end of follow-up period, 36 patients were progress, 19 patients were dead and 70 patients were still alive. The median follow-up time was 35 months. Patients' clinicopathological characteristics and the mean pretreatment level of HE4 and CA125 were presented in Table 1. The mean HE4 value of pretreatment was significantly increased with FIGO stage $(p=0.008)$ and tumor grade $(p=0.000)$. While the mean CA125 level of 
Table 1 Characteristics of patients with ovarian cancer and comparison with pretreatment HE4 and CA125 level

\begin{tabular}{|c|c|c|}
\hline Characteristics & Pretreatment HE4 Mean (range) [pmol/L] & Pretreatment CA125 Mean (range) $[\mathrm{U} / \mathrm{ml}]$ \\
\hline \multicolumn{3}{|l|}{ Menopausal } \\
\hline Premenopausal, $n=35$ & $408.8(32.4-1529)$ & $939.3(9.0-5023)$ \\
\hline Postmenopausal, $n=54$ & $548.7(47.4-4703)$ & $855.4(8.0-4423)$ \\
\hline$P$ value & 0.309 & 0.733 \\
\hline \multicolumn{3}{|l|}{ FIGO stage } \\
\hline I and $\mid 1, n=37$ & $286.7(32.4-1500)$ & $543.8(8.0-3066)$ \\
\hline III and IV, $n=52$ & $641.0(63.11-4703)$ & $1133.5(18.8-5023)$ \\
\hline$P$ value & 0.008 & 0.008 \\
\hline \multicolumn{3}{|l|}{ Tumor grade } \\
\hline $1, n=11$ & $141.2(33.6-437)$ & $472.0(9.0-2062)$ \\
\hline 2 and $3, n=78$ & $543.4(32.4-4703)$ & $947.1(683.6-1210)$ \\
\hline$P$ value & 0.000 & 0.191 \\
\hline \multicolumn{3}{|l|}{ Histology } \\
\hline Serous, $n=48$ & $618.5(47.4-4703)$ & $1152.6(8.0-5023)$ \\
\hline Mucinous, $n=7$ & $232.5(40.8-1132)$ & $139.7(12.5-523)$ \\
\hline Clear cell, $n=11$ & $193.9(32.4-675)$ & $229.4(13.0-653)$ \\
\hline Endometrioid, $n=8$ & $635.7(33.6-1529)$ & $714.9(9.0-1974)$ \\
\hline Others, $n=15$ & $360.2(81.4-1234)$ & $967.9(11.68-3643)$ \\
\hline$P$ value & 0.153 & 0.040 \\
\hline \multicolumn{3}{|l|}{ Platinum response } \\
\hline Sensitive, $n=73$ & $487.9(32.4-4703)$ & $955.2(8.0-5023)$ \\
\hline Resistant, $n=16$ & $520.2(63.11-1500)$ & 583.5 (15.6-2880) \\
\hline$P$ value & 0.854 & 0.233 \\
\hline \multicolumn{3}{|l|}{ Two-year PFS } \\
\hline YES, $n=59$ & 389.7 (32.4-2106) & $898.6(7.98-5023)$ \\
\hline $\mathrm{NO}, n=30$ & $698.1(63.11-4703)$ & $868.2(15.6-3643)$ \\
\hline$P$ value & 0.076 & 0.905 \\
\hline
\end{tabular}

pretreatment was only significant increased with FIGO stage $(p=0.008)$ and histology types $(p=0.040)$. However, there were no significant differences in menopausal, platinum response and two-year PFS with pretreatment HE4 or CA125.

\section{The predictive value of HE4 and CA125 in platinum sensitivity}

In the analyzed patients, 16 were defined as platinum resistant and 73 as platinum sensitive. The capability of HE4 and CA125 clearance after 1st, 3rd, 6th cycle chemotherapy to predict platinum sensitivity were assessed by ROC and AUC. The clearance was defined as the level of HE4/CA125 reduced to normal value or had a reduction rate of $90 \%$ at least. The early clearance was defined as the clearance of HE4/CA125 before the 4th cycle of adjuvant chemotherapy. According to the definition, we found in platinum sensitive group that the clearance of HE4 in 55 of 73 (75.3\%) cases after 1st cycle chemotherapy, in 59 of $73(80.8 \%)$ cases after 3rd cycle chemotherapy, and in 61 of $73(83.6 \%)$ cases after 6th cycle chemotherapy. The HE4 non-clearance patients of platinum resistant were found in 10 of $16(62.5 \%)$ cases after 1st cycle chemotherapy, in 12 of $16(75.0 \%)$ cases after 3rd cycle chemotherapy, and in 10 of 16 (62.5\%) cases after 6th cycle chemotherapy. The maximum AUC was 0.779 for HE4 after 3rd cycle chemotherapy, with $75.0 \%$ of sensitivity, $80.8 \%$ of specificity, and a $p$ value of 0.000. The maximum AUC was 0.731 for CA125 after 1st cycle chemotherapy, reporting $75.0 \%$ of sensitivity, $71.2 \%$ of specificity, and a $p$ value of 0.004 . When the two biomarkers were combined, the result showed that when HE4 clearance after 3rd cycle chemotherapy or CA125 clearance after 1st cycle chemotherapy, it gave the highest AUC of 0.788 , with $100 \%$ of sensitivity and $57.5 \%$ of specificity respectively. When HE4 clearance after 3rd cycle chemotherapy and CA125 clearance after 1st cycle chemotherapy were used at the same time, the 
AUC, sensitivity, and specificity were $0.723,50$, and 94.5\% respectively. The AUC, sensitivity, specificity, positive predictive value (PPV), negative predictive value (NPV), accuracy and $p$-value base on each parameter were shown in Table 2.

\section{The clearance of serum HE4 and CA125 in predicting two- year PFS}

In this part (Table 3), 59 patients were classified as twoyear PFS group and 30 as not achieved two-year PFS group according to obtaining two-year PFS or not. Using the predefined standard with the clearance of HE4 and CA125, we found in two-year PFS group that the clearance of HE4 in 45 of $59(76.3 \%)$ cases after 1st cycle chemotherapy, in 50 of 59 (84.7\%) cases after third cycle chemotherapy, and in 51 of 59 (86.4\%) cases after sixth cycle chemotherapy. The HE4 non-clearance patients of not achieved two-year PFS were found in 14 of 30 (46.7\%) cases after 1st cycle chemotherapy, in 17 of 30 (56.7\%) cases after 3rd cycle chemotherapy, and in 14 of $30(46.7 \%)$ cases after 6 th cycle chemotherapy. We found a statistically significant difference in predicting two-year PFS between patients with HE4 clearance and nonclearance at the period of after the 3rd and 6th cycle chemotherapy $(p=0.001,0.011)$, and the AUC of 0.707, 0.666 respectively (Table 3 ). The early clearance of HE4 after 3rd cycle chemotherapy demonstrated the optimal accuracy of $75.3 \%$, with a corresponding $56.7 \%$ of sensitivity and $84.7 \%$ of specificity (PPV $=65.4 \%, \mathrm{NPV}=79.4 \%$ ). The CA125 clearance profile in two-year PFS group were found in 43 of 59 (72.9\%) cases after 1st cycle chemotherapy, in 56 of 59 (94.9\%) cases after 3rd cycle chemotherapy, and in 57 of 59 (96.6\%) cases after 6th cycle chemotherapy. The CA125 non-clearance patients of not achieved two-year PFS group were found in 17 of $30(56.7 \%)$ cases after 1st cycle chemotherapy, in 7 of 30 (23.3\%) cases after 3rd cycle chemotherapy, and in 7 of 30 (23.3\%) cases after 6th cycle chemotherapy. Significant differences in predicting two-year PFS was only found in patients with CA125 clearance after the 1st cycle chemotherapy $(p=0.023)$, with the AUC of 0.648 , and a corresponding $56.7 \%$ of sensitivity and $72.9 \%$ of specificity ( $\mathrm{PPV}=51.5 \%, \mathrm{NPV}=76.8 \%)$. When HE4 and CA125 were combined, it was shown that the AUC reached 0.730 when the HE4 value after 3rd cycle chemotherapy or the CA125 after 1st cycle chemotherapy that declined above $90 \%$ or normalized $(p=0.000)$. However, when both of the HE4 after 3rd cycle chemotherapy and the CA125 after 1st cycle chemotherapy declined above $90 \%$ or normalization, the AUC was 0.625 with $p=0.056$.

\section{The relationship between prognosis and the serum HE4 and CA125}

The Kaplan-Meier survival curve and a log rank test were conducted to analyze the relationship between patient's PFS/OS and the value of HE4 and CA125 (Fig. 1). The result showed that the prolonged PFS and OS were significantly associated with the clearance of HE4 after 3rd cycle chemotherapy $(p<0.0001, p<0.0001)$ and CA125 after 1st cycle chemotherapy $(p<0.0001, p<$ $0.0001)$. The pretreatment levels of HE4 had an impact on the PFS $(p=0.014)$. However, there were no statistical significance between pretreatment levels of CA125 with PFS $(p=0.694)$ and also no statistical significance between pretreatment HE4 and CA125 with OS $(p=0.172$, $p=0.341)$.

Table 2 Classification base on the platinum response and the AUC value using the clearance of HE4 and CA125

\begin{tabular}{|c|c|c|c|c|c|c|c|c|c|}
\hline & Platinum sensitive & Platinum resistant & Sensitivity & Specificity & PPV & NPV & Accuracy & $\begin{array}{l}P \text { - } \\
\text { value }\end{array}$ & AUC \\
\hline & HE4 clearance & HE4 non-clearance & & & & & & & \\
\hline 1 cycle & 55/73 (75.3\%) & $10 / 16(62.5 \%)$ & $62.5 \%$ & $75.3 \%$ & $35.7 \%$ & $90.2 \%$ & $73.0 \%$ & 0.018 & 0.689 \\
\hline 3 cycle & $59 / 73(80.8 \%)$ & $12 / 16(75.0 \%)$ & $75.0 \%$ & $80.8 \%$ & $54.5 \%$ & $93.7 \%$ & $79.8 \%$ & 0.000 & 0.779 \\
\hline \multirow[t]{2}{*}{6 cycle } & 61/73 (83.6\%) & $10 / 16(62.5 \%)$ & $62.5 \%$ & $83.6 \%$ & $45.5 \%$ & $91.0 \%$ & $79.8 \%$ & 0.004 & 0.730 \\
\hline & CA125 clearance & CA125 non-clearance & & & & & & & \\
\hline 1 cycle & $52 / 73(71.2 \%)$ & $12 / 16(75.0 \%)$ & $75.0 \%$ & $71.2 \%$ & $36.4 \%$ & $92.9 \%$ & $71.9 \%$ & 0.004 & 0.731 \\
\hline 3 cycle & 69/73 (94.5\%) & $6 / 16(37.5 \%)$ & $37.5 \%$ & $94.5 \%$ & $60.0 \%$ & $87.3 \%$ & $84.3 \%$ & 0.046 & 0.660 \\
\hline \multirow[t]{2}{*}{6 cycle } & 71/73 (97.3\%) & 6/16 (43.8\%) & $43.8 \%$ & $97.3 \%$ & $77.8 \%$ & $88.8 \%$ & $87.6 \%$ & 0.011 & 0.705 \\
\hline & HE4 or CA125 clearance & Both HE4 and CA125 n & n-clearance & & & & & & \\
\hline \multirow{2}{*}{$\begin{array}{l}3 \text { cycle of HE } 4 \text { or } 1 \text { cycle } \\
\text { of CA } 125\end{array}$} & $42 / 73(57.5 \%)$ & $16 / 16(100 \%)$ & $100.0 \%$ & $57.5 \%$ & $34.0 \%$ & $100.0 \%$ & $65.2 \%$ & 0.000 & 0.788 \\
\hline & $\begin{array}{l}\text { Both HE4 and CA125 } \\
\text { clearance }\end{array}$ & $\begin{array}{l}\text { HE4 or CA125 non- } \\
\text { clearance }\end{array}$ & & & & & & & \\
\hline $\begin{array}{l}3 \text { cycle of HE4 and } 1 \text { cycle } \\
\text { of CA } 125\end{array}$ & 69/73 (94.5\%) & $8 / 16(50.0 \%)$ & $50.0 \%$ & $94.5 \%$ & $66.7 \%$ & $89.6 \%$ & $86.5 \%$ & 0.005 & 0.723 \\
\hline
\end{tabular}


Table 3 Classification base on the two-year PFS and the AUC value using the clearance of HE4 and CA125

\begin{tabular}{|c|c|c|c|c|c|c|c|c|c|}
\hline & \multicolumn{2}{|l|}{ Two-year PFS } & \multirow[t]{2}{*}{ Sensitivity } & \multirow[t]{2}{*}{ Specificity } & \multirow[t]{2}{*}{ PPV } & \multirow[t]{2}{*}{ NPV } & \multirow[t]{2}{*}{ Accuracy } & \multirow{2}{*}{$\begin{array}{l}P \text { - } \\
\text { value }\end{array}$} & \multirow[t]{2}{*}{ AUC } \\
\hline & Yes & No & & & & & & & \\
\hline & HE4 clearance & HE4 non-clearance & & & & & & & \\
\hline 1 cycle & 45/59 (76.3\%) & 14/30 (46.7\%) & $46.7 \%$ & $76.3 \%$ & $50.0 \%$ & $73.8 \%$ & $66.3 \%$ & 0.078 & 0.615 \\
\hline 3 cycle & $50 / 59(84.7 \%)$ & $17 / 30(56.7 \%)$ & $56.7 \%$ & $84.7 \%$ & $65.4 \%$ & $79.4 \%$ & $75.3 \%$ & 0.001 & 0.707 \\
\hline \multirow[t]{2}{*}{6 cycle } & $51 / 59(86.4 \%)$ & $14 / 30(46.7 \%)$ & $46.7 \%$ & $86.4 \%$ & $63.6 \%$ & $76.1 \%$ & $73.0 \%$ & 0.011 & 0.666 \\
\hline & CA125 clearance & CA125 non-clearance & & & & & & & \\
\hline 1 cycle & 43/59 (72.9\%) & $17 / 30(56.7 \%)$ & $56.7 \%$ & $72.9 \%$ & $51.5 \%$ & $76.8 \%$ & $67.4 \%$ & 0.023 & 0.648 \\
\hline 3 cycle & $56 / 59(94.9 \%)$ & $7 / 30(23.3 \%)$ & $23.3 \%$ & $94.9 \%$ & $70.0 \%$ & $70.9 \%$ & $70.8 \%$ & 0.161 & 0.591 \\
\hline \multirow[t]{2}{*}{6 cycle } & $57 / 59(96.6 \%)$ & $7 / 30(23.3 \%)$ & $23.3 \%$ & $96.9 \%$ & $77.8 \%$ & $71.3 \%$ & $71.9 \%$ & 0.126 & 0.600 \\
\hline & HE4 or CA125 clearance & Both HE4 and CA125 nc & clearance & & & & & & \\
\hline \multirow{2}{*}{$\begin{array}{l}3 \text { cycle of HE4 or } 1 \text { cycle } \\
\text { of CA } 125\end{array}$} & $37 / 59(62.7 \%)$ & 25/30 (83.3\%) & $83.3 \%$ & $62.7 \%$ & $53.2 \%$ & $88.1 \%$ & $69.7 \%$ & 0.000 & 0.730 \\
\hline & $\begin{array}{l}\text { Both HE4 and CA125 } \\
\text { clearance }\end{array}$ & $\begin{array}{l}\text { HE4 or CA125 non- } \\
\text { clearance }\end{array}$ & & & & & & & \\
\hline $\begin{array}{l}3 \text { cycle of HE4 and } 1 \text { cycle } \\
\text { of CA } 125\end{array}$ & $56 / 59(94.9)$ & 9/30 (30.0\%) & $30.0 \%$ & $94.9 \%$ & $75.0 \%$ & $72.7 \%$ & $73.0 \%$ & 0.056 & 0.625 \\
\hline
\end{tabular}

Univariate and multivariate cox regress analysis were explored to analyze the widely recognized prognostic of EOC, as well as the early clearance of HE4 and CA125 (Table 4). The univariate analysis demonstrated a significant influence of stage, HE4-clearance after 3rd cycle of chemotherapy, and CA125-clearance after 1st cycle of chemotherapy with respect to both OS and PFS in patients. Multivariate analysis revealed that only the HE4clearance after 3rd cycle of chemotherapy and CA125clearance after 1st cycle of chemotherapy were significantly independently associated with OS. The prolongation of PFS was significantly influenced by the stage, HE4-median pretreatment, HE4-clearance after 3rd cycle of chemotherapy, and CA125-clearance after 1st cycle of chemotherapy.

\section{Discussion}

To our knowledge, optimal tumor debulking and platinum response have been proven to be the most powerful prognostic factor for both overall survival and progression-free survival of ovarian cancer patients. To acquire optimal tumor debulking, multivisceral resection including en bloc resections with bowel resection, upper abdominal procedures, and extensive peritonectomy are required when necessary. Despite improvement in surgical techniques, there are still patients who are not obtain radical resection will develop platinum-resistance with poor prognosis. At present, CA125 are conventionally used in monitoring responds to surgery and chemotherapy for ovarian cancer patients. Data from GOG-182 showed that the median OS for patients whose CA125 value declined to normal level after 2nd cycle chemotherapy was 77.7 months, compared with 23.0 months for those who did not normalized, and improved PFS was observed in patients with CA125 value declined to normal level after 1st, 2nd or 3rd cycle chemotherapy compared to those who never normalized before 4th cycle chemotherapy [12].

HE4 is a novel tumor biomarker in EOC patients. The assessment of the prognostic significance of pretreatment HE4 has been described in many papers. However, few studies focused on the early clearance of HE4 after treatment in predicting prognosis of epithelial ovarian cancer. There were several results suggested that HE4 was mainly secreted by malignant ovarian cancer cell and tumor micro-environment $[13,18]$. Therefore, the removal of the tumor and the response to treatment should correlate with the clearance of HE4.

A prospective study of Roberto Angioli suggested that HE4 reduction with above $47 \%$ at the third cycle of chemotherapy were more likely to be platinum sensitive. On the contrary, CA125 value did not correlate with platinum response [1]. In our recent study, we have demonstrated that single HE4 superior to CA125 in predicting platinum sensitivity. Our data showed that the maximum AUC value of HE4 alone was $0.779(p=0.000)$ in predicting platinum sensitivity after the third cycle chemotherapy compared to the maximum $\mathrm{AUC}=0.731$ of CA125 $(p=0.004)$ after 1st cycle chemotherapy respectively. When the two biomarkers were combined, the result showed that when HE4 clearance after 3rd cycle chemotherapy or CA125 clearance after 1st cycle chemotherapy, the AUC, sensitivity and specificity were $0.788,100$ and $57.5 \%$ respectively. It means that $100 \%$ patients with platinum resistant could be identified through the both non-clearance of HE4 after 3rd cycle 
A

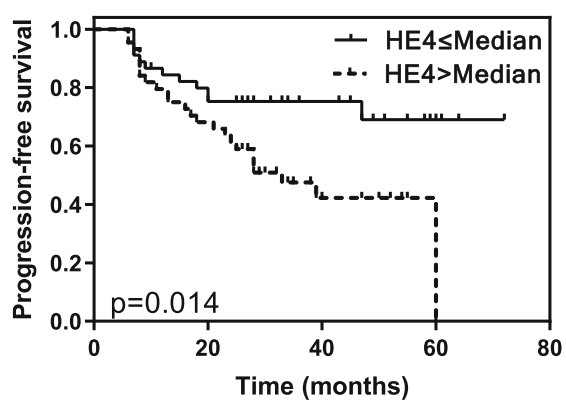

C

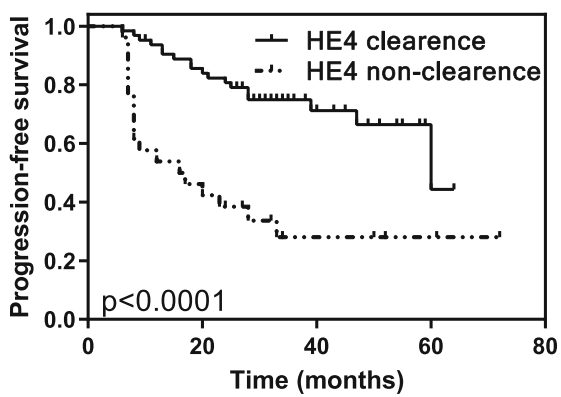

E

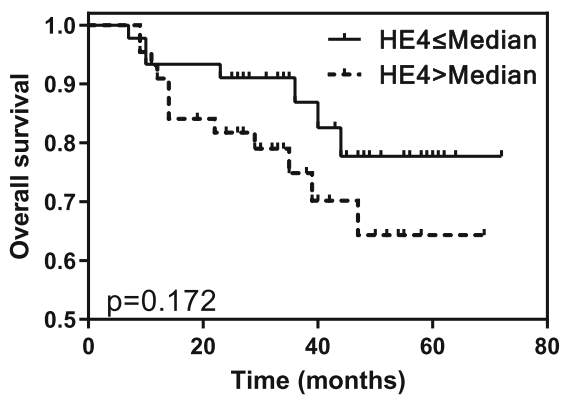

G

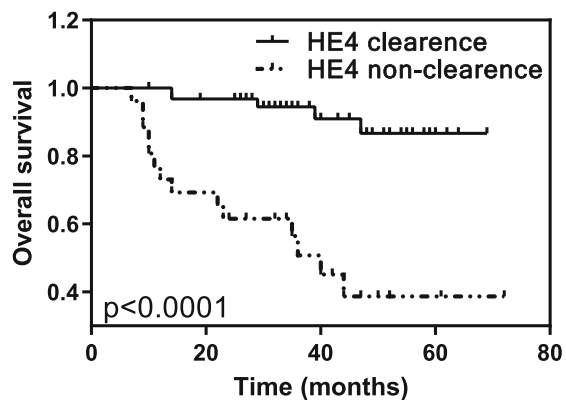

B

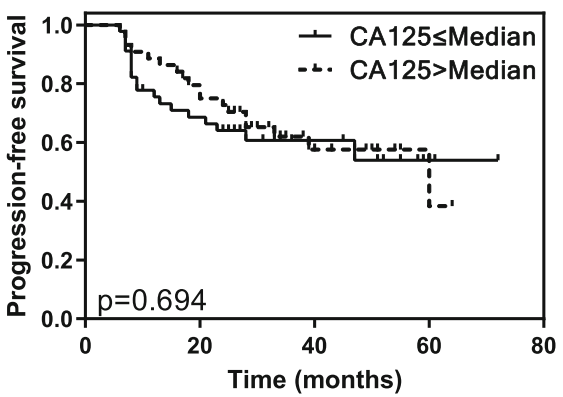

D

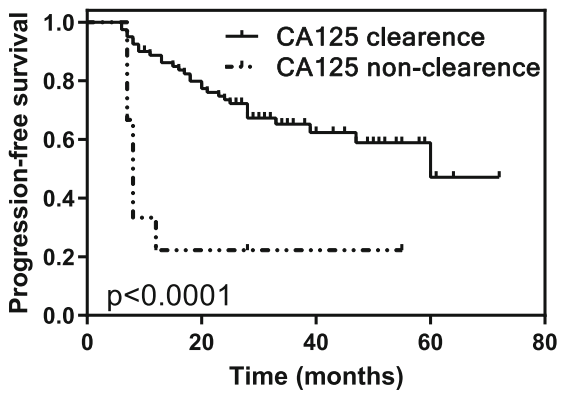

F

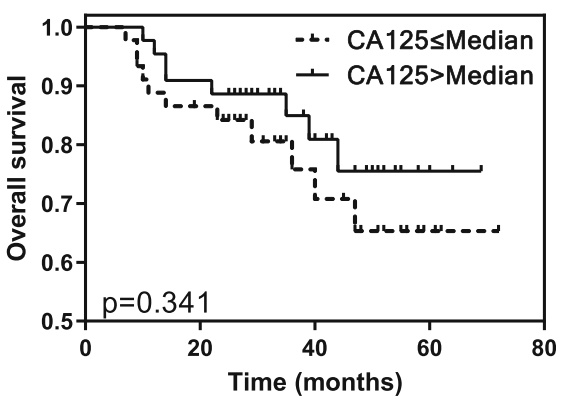

H

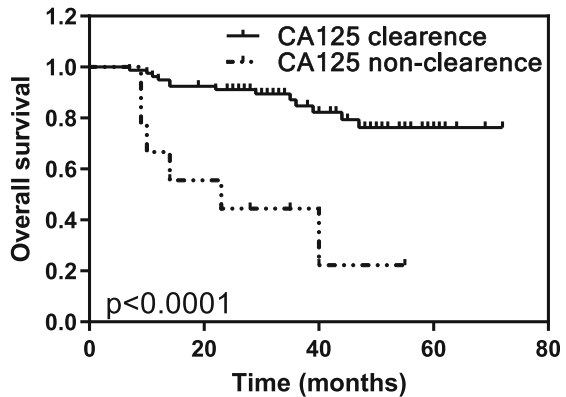

Fig. 1 Correlation between the HE4 and CA125 level and OS/PFS. Kaplan-meier curve presenting the OS/PFS with different stratification of HE4 and CA125, including $\mathbf{a}$ The median of pretreatment HE4. $\mathbf{b}$ The median of pretreatment CA125. $\mathbf{c}$ The clearance of 3rd cycle chemotherapy. $\mathbf{d}$ The clearance of 1st cycle chemotherapy. e The median of pretreatment HE4. $\mathbf{f}$ The median of pretreatment CA125. $\mathbf{g}$ The clearance of 3rd cycle chemotherapy. $\mathbf{h}$ The clearance of 1 st cycle chemotherapy 
Table 4 Univariate and multivariate analyses for OS and PFS

\begin{tabular}{|c|c|c|c|c|c|c|c|c|}
\hline & \multicolumn{4}{|l|}{ Univariate analysis } & \multicolumn{4}{|c|}{ Multivariate analysis } \\
\hline & \multicolumn{2}{|l|}{ OS } & \multicolumn{2}{|l|}{ PFS } & \multicolumn{2}{|l|}{ OS } & \multicolumn{2}{|l|}{ PFS } \\
\hline & $\mathrm{HR}(95 \% \mathrm{Cl})$ & $\begin{array}{l}p- \\
\text { value }\end{array}$ & $\mathrm{HR}(95 \% \mathrm{Cl})$ & $\begin{array}{l}p- \\
\text { value }\end{array}$ & $\mathrm{HR}(95 \% \mathrm{Cl})$ & $\begin{array}{l}p- \\
\text { value }\end{array}$ & $\mathrm{HR}(95 \% \mathrm{Cl})$ & $\begin{array}{l}p- \\
\text { value }\end{array}$ \\
\hline Age & $1.033(0.988-1.080)$ & 0.155 & $\begin{array}{l}1.001(0.969- \\
1.035)\end{array}$ & 0.931 & & & & \\
\hline Grade 1 vs. grade 2,3 & $\begin{array}{l}3.566(0.474- \\
26.854)\end{array}$ & 0.217 & $\begin{array}{l}1.862(0.570- \\
6.080)\end{array}$ & 0.303 & & & & \\
\hline Stage & $1.946(1.096-3.455)$ & 0.023 & $\begin{array}{l}2.092(1.385- \\
3.161)\end{array}$ & 0.000 & & & $\begin{array}{l}1.877(1.154- \\
3.052)\end{array}$ & 0.011 \\
\hline $\begin{array}{l}\text { Serous vs. other } \\
\text { histopathology }\end{array}$ & $1.114(0.452-2.745)$ & 0.814 & $\begin{array}{l}0.815(0.417- \\
1.595)\end{array}$ & 0.550 & & & & \\
\hline HE4-median pretreatment & $1.893(0.744-4.815)$ & 0.181 & $\begin{array}{l}2.325(1.157- \\
4.673)\end{array}$ & 0.018 & & & $\begin{array}{l}2.315(1.084- \\
4.941)\end{array}$ & 0.030 \\
\hline $\begin{array}{l}\text { HE4-clearance after 3rd cycle } \\
\text { of chemotherapy }\end{array}$ & $\begin{array}{l}8.295(2.984- \\
23.057)\end{array}$ & 0.000 & $\begin{array}{l}3.632(1.877- \\
7.027)\end{array}$ & 0.000 & $\begin{array}{l}8.294(2.980- \\
23.085)\end{array}$ & 0.000 & $\begin{array}{l}2.713(1.361- \\
5.407)\end{array}$ & 0.005 \\
\hline CA125-median pretreatment & $0.645(0.259-1.606)$ & 0.346 & $\begin{array}{l}0.878(0.456- \\
1.690)\end{array}$ & 0.697 & & & & \\
\hline $\begin{array}{l}\text { CA125-clearance after 1st cycle } \\
\text { of chemotherapy }\end{array}$ & $\begin{array}{l}2.556(1.4027- \\
6.361)\end{array}$ & 0.044 & $\begin{array}{l}2.435(1.260- \\
4.709)\end{array}$ & 0.008 & 2.549 (1.019-6.378) & 0.045 & $\begin{array}{l}3.853(1.888- \\
7.865)\end{array}$ & 0.000 \\
\hline
\end{tabular}

chemotherapy and CA125 after 1st cycle chemotherapy. When HE4 after 3rd cycle chemotherapy and CA125 after 1st cycle chemotherapy were both clearance, $94.5 \%$ individual with platinum sensitive could be recognized. Previous publications on the application of HE4 and CA125 as a method of predicting chemotherapy response have mainly focused on the pretreatment biomarker value $[1,4,5,20]$. Anita et al. have reported that the predictive abilities with regard to platinum sensitivity for pretreatment HE4 was excellent with an AUC of 0.627, and poor for pretreatment CA125 with an AUC of 0.547 respectively [4]. Nassir et al. showed that high level of pretreatment HE4 and CA125 correlated significantly with a poor response to platinum based chemotherapy [20]. Few studies pay attention to the dynamic change of biomarker corresponding to treatment response during first-line treatment. Chen et al. concluded that the change of HE4 was more closely related to the chemotherapy response compared to the change of CA125 individually [3]. Vallius et al. presented their result that HE4 was a reliable serum tumor marker for monitoring treatment response in advanced EOC patients [27]. They focused on the postoperative level and the nadir value during postoperative chemotherapy with serum HE4 and CA125. Their result suggested that the single postoperative HE4 was associated to residual tumor after surgery, primary therapy outcome and PFS in both primary debulking surgery (PDS) and interval debulking surgery (IDS) patients. The single postoperative CA125 was associated to PFS after IDS but not for PDS. They also demonstrated that the combination of HE4 and CA125 nadir level predicted primary treatment outcome and PFS better than either alone. However, they didn't refer the combination of the clearance speed of HE4 and CA125 in predicting treatment response and prognosis. In Pelissier' report, the cut-off for CA125 of $35 \mathrm{UI} / \mathrm{ml}$ and combined with HE4 of $115 \mathrm{pmol} / \mathrm{L}$ after the 3rd cycle of neoadjuvant chemotherapy (NACT) has a sensitivity of $92.9 \%$ and a specificity of $68.7 \%$ (PPV= $72.2 \%$ and $\mathrm{NPV}=91.7 \%$ ) in predicting platinum sensitivity in a small cohort of 30 patients deemed inoperable with advanced EOC [21]. Our study is the first to evaluate the predicting effect of treatment response and platinum sensitivity with the combination of early clearance of HE4 and CA125 during first-line chemotherapy. Our results suggest that monitoring HE4 and CA125 during first-line chemotherapy should be recommended. It may help early identifying high-risk patients with platinumresistant in EOC patients. In other words, for this part of high-risk patients with a slow decline in HE4 and CA125, the corresponding imaging evaluation or individualized treatment should be developed. At present, there are no clinical trials showing that modifying the treatment based on the unsatisfactory decline of serological tumor biomarkers after treatment can improve the outcome of patients. HE4 and CA125 appear to be able to select high-risk patients who demand further treatment base on their adverse features, but still need to be confirmed in larger studies.

Olivier Colomban et al. used a Kelim model [26], which characterize the CA125 elimination rate during the first 100 days of NACT and adjuvant chemotherapy, to assess the benefit in survival with bevacizumab addition for highrisk ovarian cancer patients in ICON-7 [9]. The result 
showed that only those high-risk patients with an unfavorable KELIM parameter less than 1.0 might have derived a benefit from bevacizumab when considering non-censored median survivals. With respect to HE4, previous study showed that patients with HE4 change of $>80 \%$ during NACT in advance high-grade serous ovarian cancer correlated with prolonged OS compared to change $<80 \%$ [28]. However, serum CA125 decline of $>80$ and $<80 \%$ during NACT had no statistical significance in OS. Patients with CA125 logarithmic decrease or normalization within 1 month post-operative were correlated with better PFS and OS [25]. Our data also demonstrated that serum HE4 is a more promising biomarker in prognosis of EOC compared to CA125. In the ROC curve analysis, patients with HE4 level normalization or reduction above $90 \%$ after 3rd and 6th cycle chemotherapy significantly correlated with twoyear PFS (AUC $=0.707, p=0.001$, and $\mathrm{AUC}=0.666, p=0.011$ ). CA125 level normalization or reduction above $90 \%$ after 1st cycle chemotherapy correlated with two-year PFS, with a lower AUC of $0.648, p=0.023$. When combination of the HE4 after 3rd cycle chemotherapy and CA125 after 1st cycle chemotherapy, it was shown that the AUC reached to 0.730 when one of them declined above $90 \%$ or normalized ( $p=0.000$ ), reporting an $83.3 \%$ of sensitivity and a $62.7 \%$ of specificity. Approximately $83.3 \%$ of patient who relapsed or progressed in 2 years could be identified during first-line chemotherapy with a $62.7 \%$ of specificity based on the combination of HE4 and CA125 non-early clearance. Using biomarkers to identify high-risk patients was a simple and non-invasive way and may complement the current definition of high-risk patients.

The result of Kaplan-Meier survival curve and long rank test also demonstrated that both the clearance of HE4 after 3rd cycle chemotherapy and CA125 after 1st cycle chemotherapy were significantly correlation with the PFS and OS. Prolonged PFS was significantly impacted by the pretreatment HE4 value but not pretreatment CA125. As respected to OS, there were no significant correlation between pretreatment value of HE4 and CA125 in our results. Similar results were obtained in other research which analyzed the influence of the pretreatment HE4 on PFS [12, 14, 15, 24]. Amanda Fader et al. analyzed a group of 3686 patients with ovarian cancer and demonstrated that there was no difference in pretreatment CA125 with outcome [12]. However, patients with CA125 that normalized after 1st, 2nd, 3rd cycle of chemotherapy treatment were less likely to experience disease progression as compared to those of not normalization ones in Fader' study. Anita et al. analyzed a group of 48 EOC patients treated with PDS and demonstrated that the prolongation of PFS and OS was significantly correlated with the pre-operative HE4 value [4]. Their result also concluded that the duration of OS was significantly influenced by the HE4 value after the third course of chemotherapy but not CA125, and the prolonged PFS was influenced by the CA125 value after the third course of chemotherapy treatment bot not the HE4. This result was different from ours. The reason for this problem may be due to its small sample size and selection bias.

This study was a retrospective character, single-center setting, relatively small number of patients, and lack of external validation, which may bias the results. A bigger prospective cohort or including more clinical covariate such as ECOG score, oncogene expression might be helpful to validate the result and provide more information. Therefore, further studies are needed to confirm these results.

\section{Conclusions}

In conclusions, our findings revealed that the early clearance of HE4 and CA125 during first-line platinum chemotherapy were significantly associated with the platinum sensitivity and prognosis. Monitoring the dynamic value of both HE4 and CA125 during treatment might be helpful in future clinical practice.

\begin{abstract}
Abbreviations
HE4: Human epididymis protein 4; CA125: Cancer antigen 125; EOC: Epithelial ovarian cancer; ADP: Adenosine Diphosphate; FIGO: The International

Federation of Obstetrics and Gynecology Staging System; PFS: Progressionfree survival; OS: Overall survival; Cl: Confidence interval; GCIG: The

Gynecology Cancer Intergroup; RECIST: The Response Evaluation Criteria in Solid Tumors; AUC: Area under the curve; ROC: Receive operator

characteristics; PPV: Positive predictive value; NPV: Negative predictive value; PDS: Primary debulking surgery; IDS: Interval debulking surgery;

NACT: Neoadjuvant chemotherapy; ECOG: Eastern Cooperative Oncology Group
\end{abstract}

\section{Acknowledgements}

Not applicable.

\section{Authors' contributions}

First author: Yan Rong was responsible for statistical analysis of data and the manuscript writing. Corresponding author: Li Li was responsible for the revision. The final manuscript was approved by all authors.

\section{Funding}

This work was supported by grants from the Key Laboratory of Early Prevention \& Treatment of Regional High-Incidence-Tumor, Ministry of Education of China, the Innovation Project of Guangxi Graduate Education (Grant No. YCBZ2020051), and Guangxi zhuang autonomous region clinical key specialized subject construction project funds. The funder had no role in study design, data collection and analysis, decision to publish, or preparation of the manuscript.

\section{Availability of data and materials}

The data and materials which were analyzed and generated at the study are available from the corresponding author on reasonable request.

\section{Ethics approval and consent to participate}

The study was reviewed by the Ethics Committee of Guangxi Medical University Cancer Hospital, and was considered that the research met the requirements of medical ethics (Number: LW2020080). The written informed consents of all treatments and examinations were obtained from patients or their families. 


\section{Consent for publication}

Not applicable.

\section{Competing interests}

The authors declare that they have no competing of interests.

Received: 17 July 2020 Accepted: 21 December 2020

Published online: 04 January 2021

\section{References}

1. Angioli R, Capriglione S, Aloisi A, et al. Can HE4 predict platinum response during first-line chemotherapy in ovarian cancer? Tumour Biol. 2014;35(7): 7009-15. https://doi.org/10.1007/s13277-014-1836-x.

2. Bray F, Ferlay J, Soerjomataram I, et al. Global cancer statistics 2018: GLOBOCAN estimates of incidence and mortality worldwide for 36 cancers in 185 countries. CA Cancer J Clin. 2018;68(6):394-424. https://doi.org/10. 3322/caac.21492

3. Chen WT, Gao X, Han XD, et al. HE4 as a serum biomarker for ROMA prediction and prognosis of epithelial ovarian cancer. Asian Pac J Cancer Prev. 2014;15(1):101-5. https://doi.org/10.7314/apjcp.2014.15.1.101.

4. Chudecka-Glaz A, Cymbaluk-Ploska A, Wezowska M, et al. Could HE4 level measurements during first-line chemotherapy predict response to treatment among ovarian cancer patients? PLoS One. 2018;13(3):e0194270. https://doi.org/10.1371/journal.pone.0194270.

5. Chudecka-Glaz AM, Cymbaluk-Ploska AA, Menkiszak JL, et al. Serum HE4, CA125, YKL-40, bcl-2, cathepsin-L and prediction optimal debulking surgery, response to chemotherapy in ovarian cancer. J Ovarian Res. 2014; 7:62. dol: https://doi.org/10.1186/1757-2215-7-62.

6. Chudecka-Glaz A, Rzepka-Gorska I, Wojciechowska I. Human epididymis protein 4 (HE4) is a novel biomarker and a promising prognostic factor in ovarian cancer patients. Eur J Gynaecol Oncol. 2012:33(4):382-90.

7. Coleman RL, Gordon A, Barter J, et al. Early changes in CA125 after treatment with pegylated liposomal doxorubicin or topotecan do not always reflect best response in recurrent ovarian cancer patients. Oncologist. 2007:12(1):72-8. https://doi.org/10.1634/theoncologist.12-1-72.

8. Colombo N, Peiretti M, Parma G, et al. Newly diagnosed and relapsed epithelial ovarian carcinoma: ESMO clinical practice guidelines for diagnosis, treatment and follow-up. Ann Oncol. 2010;21(Suppl 5):v23-30. https://doi. org/10.1093/annonc/mdq244

9. Colomban O, Tod M, Peron J, et al. Bevacizumab for newly diagnosed ovarian cancers: best candidates among high-risk disease patients (ICON-7). JNCI Cancer Spectr. 2020;4(3):pkaa026. https://doi.org/10.1093/jncics/ pkaa026.

10. Dai C, Zheng Y, Li Y, et al. Prognostic values of HE4 expression in patients with cancer: a meta-analysis. Cancer Manag Res. 2018;10:4491-500. https:// doi.org/10.2147/CMAR.S178345.

11. Eisenhauer EA, Therasse P, Bogaerts J, et al. New response evaluation criteria in solid tumours: revised RECIST guideline (version 1.1). Eur J Cancer. 2009; 45(2):228-47. https://doi.org/10.1016/j.ejca.2008.10.026.

12. Fader AN, Java J, Krivak TC, et al. The prognostic significance of pre- and post-treatment CA-125 in grade 1 serous ovarian carcinoma: a gynecologic oncology group study. Gynecol Oncol. 2014;132(3):560-5. https://doi.org/10. 1016/j.ygyno.2013.11.016

13. Hellstrom I, Raycraft J, Hayden-Ledbetter M, et al. The HE4 (WFDC2) protein is a biomarker for ovarian carcinoma. Cancer Res. 2003:63(13):3695-700.

14. Kaijser J, Van Belle V, Van Gorp T, et al. Prognostic value of serum HE4 levels and risk of ovarian malignancy algorithm scores at the time of ovarian cancer diagnosis. Int J Gynecol Cancer. 2014;24(7):1173-80. https://doi.org/ 10.1097/IGC.0000000000000181.

15. Kong SY, Han MH, Yoo HJ, et al. Serum HE4 level is an independent prognostic factor in epithelial ovarian cancer. Ann Surg Oncol. 2012;19(5): 1707-12. https://doi.org/10.1245/s10434-011-1943-5.

16. Lee $\mathrm{S}$, Choi $\mathrm{S}$, Lee $\mathrm{Y}$, et al. Role of human epididymis protein 4 in chemoresistance and prognosis of epithelial ovarian cancer. J Obstet Gynaecol Res. 2017;43(1):220-7. https://doi.org/10.1111/jog.13181.

17. Le T, Hopkins L, Faught W, et al. The lack of significance of CA125 response in epithelial ovarian cancer patients treated with neoadjuvant chemotherapy and delayed primary surgical debulking. Gynecol Oncol. 2007;105(3):712-5. https://doi.org/10.1016/j.ygyno.2007.02.022.

18. Montagnana $M$, Danese $E_{1}$ Giudici $\mathrm{S}$, et al. HE4 in ovarian cancer: from discovery to clinical application. Adv Clin Chem. 2011;55:1-20.
19. Moore RG, Brown AK, Miller MC, et al. The use of multiple novel tumor biomarkers for the detection of ovarian carcinoma in patients with a pelvic mass. Gynecol Oncol. 2008;108(2):402-8. https://doi.org/10.1016/j.ygyno. 2007.10.017.

20. Nassir M, Guan J, Luketina $H$, et al. The role of HE4 for prediction of recurrence in epithelial ovarian cancer patients-results from the OVCAD study. Tumour Biol. 2016;37(3):3009-16. https://doi.org/10.1007/s13277015-4031-9.

21. Pelissier A, Roulot A, Guéry B, et al. Serum CA125 and HE4 levels as predictors for optimal interval surgery and platinum sensitivity after neoadjuvant platinum-based chemotherapy in patients with advanced epithelial ovarian cancer. J Ovarian Res. 2016;9:61. https://doi.org/10.1186/ s13048-016-0270-7.

22. Plotti F, Guzzo F, Schiro T, et al. Role of human epididymis protein 4 (HE4) in detecting recurrence in CA125 negative ovarian cancer patients. Int J Gynecol Cancer. 2019;29(4):768-71. https://doi.org/10.1136/ijgc-2019-000211.

23. Rustin GJ, Quinn $M$, Thigpen $T$, et al. Re: new guidelines to evaluate the response to treatment in solid tumors (ovarian cancer). J Natl Cancer Inst. 2004;96(6):487-8. https://doi.org/10.1093/jnci/djh081.

24. Trudel D, Tetu B, Gregoire J, et al. Human epididymis protein 4 (HE4) and ovarian cancer prognosis. Gynecol Oncol. 2012;127(3):511-5. https://doi.org/ 10.1016/j.ygyno.2012.09.003.

25. Yang ZJ, Zhao BB, Li L. The significance of the change pattern of serum CA125 level for judging prognosis and diagnosing recurrences of epithelial ovarian cancer. J Ovarian Res. 2016;9(1):57. https://doi.org/10.1186/s13048016-0266-3.

26. You B, Colomban $\mathrm{O}$, Heywood M, et al. The strong prognostic value of KELI M, a model-based parameter from CA 125 kinetics in ovarian cancer: data from CALYPSO trial (a GINECO-GCIG study). Gynecol Oncol. 2013;130(2):28994. https://doi.org/10.1016/j.ygyno.2013.05.013.

27. Vallius T, Hynninen J, Auranen A, et al. Postoperative human epididymis protein 4 predicts primary therapy outcome in advanced epithelial ovarian cancer. Tumour Biol. 2017;39:1-8. https://doi.org/10.1177/ 1010428317691189.

28. Vallius T, Hynninen J, Auranen A, et al. Serum HE4 and CA125 as predictors of response and outcome during neoadjuvant chemotherapy of advanced high-grade serous ovarian cancer. Tumour Biol. 2014;35(12):12389-95. https://doi.org/10.1007/s13277-014-2553-1.

29. Wang J, Gao J, Yao H, et al. Diagnostic accuracy of serum HE4, CA125 and ROMA in patients with ovarian cancer: a meta-analysis. Tumour Biol. 2014; 35(6):6127-38. https://doi.org/10.1007/s13277-014-1811-6.

\section{Publisher's Note}

Springer Nature remains neutral with regard to jurisdictional claims in published maps and institutional affiliations.

Ready to submit your research? Choose BMC and benefit from:

- fast, convenient online submission

- thorough peer review by experienced researchers in your field

- rapid publication on acceptance

- support for research data, including large and complex data types

- gold Open Access which fosters wider collaboration and increased citations

- maximum visibility for your research: over $100 \mathrm{M}$ website views per year

At $\mathrm{BMC}$, research is always in progress.

Learn more biomedcentral.com/submissions 